\title{
Особенности минерального и химического состава пород архейского ультрамафит-мафитового комплекса Патчемварек-Северный
}

\author{
Морозова Л.Н., Рундквист Т.В. \\ ГИ КНЦРАН, Anamumbl,morozova@geoksc.apatity.ru,rund@geoksc.apatity.ru
}

\begin{abstract}
Аннотация. В статье приводятся данные о минеральном составе, содержании петрогенных и редких элементов в архейских ультрамафит-мафитовых массивах Патчемварек и Северный, расположенных в непосредственной близости от регионального глубинного разлома, отделяющего Мурманский блок от зеленокаменного пояса Колмозеро-Воронья. Метаперидотиты, метагаббро и метаанортозиты массивов Патчемварек и Северного, представляют собой дифференциаты единого магматического расплава и слагают расслоенный комплекс, включающий ультраосновные и основные кумулаты. Высокое значение магнезиальности в метаперидотитах $(\mathrm{mg} \#=0.85)$ относительно метагаббро $(\mathrm{mg} \#=0.57)$ и метаанортозитов $(\mathrm{mg} \#=0.34)$ коррелируется с повышенными содержаниями Со и $\mathrm{Ni}$ и пониженными содержаниями высокозарядных (Zr, Hf, Cs, Nb, Y, $\mathrm{Th}, \mathrm{U}, \mathrm{REE})$ и крупноионных литофильных (Ba, Rb, Sr, K) элементов.

Ключевые слова: габбро, анортозиты, перидотиты, архей, редкие и редкоземельные элементы, Кольский полуостров.
\end{abstract}

\section{Features of the mineral and chemical composition of rocks from the Archean Patchchvarek-Severny ultramafic-mafic complex}

\author{
Morozova L.N., Rundkvist T.V. \\ Geological institute KSC RAS, Apatity, morozova@geoksc.apatity.ru, rund@geoksc.apatity.ru
}

\begin{abstract}
The article presents data on the mineral composition, content of petrogenic, rare elements in the Archean Patchechvarek and Severny ultramafic-mafic massifs located in a close proximity to the regional deep fault separating the Murmansk block from the Kolokmozero-Voronya greenstone belt. Metaperidotites, metagabbro and metaanorthozites of the Patchemvarek and Severny massifs occur as differentiates of a single magmatic melt and compose a layered complex of ultrabasic and basic cumulates. The high magnesium content in metaperidotites $(\mathrm{mg} \#=0.85)$ is correlated with some increased metagabbro $(\mathrm{mg} \#=0.57)$ and metaanorthosites $(\mathrm{mg} \#=0.34)$, contents of $\mathrm{Co}$, Ni and decreased by high field strength elements ( $\mathrm{Zr}, \mathrm{Hf}, \mathrm{Nb}, \mathrm{Y}, \mathrm{Th}, \mathrm{U}, \mathrm{REE}$ ) and large-ion lithophile elements (Ba, Rb, Sr, K).
\end{abstract}

Key words: gabbro, anorthosites, peridotites, Archean, rare and rare earth elements, Kola Peninsula.

\section{Введение}

Массивы Большой Патчемварек, Малый Патчемварек, Северный и ещё несколько более мелких тел расположены в зоне сочленения двух крупных региональных структур архейского возраста - Мурманского блока и зеленокаменного пояса Колмозеро-Воронья. В последние годы большой интерес к интрузивному комплексу Патчемварек-Северный связан с возобновлением исследований Колмозерского литиевого месторождения. Колмозерское месторождение редкометальных пегматитов локализовано в метагаббро-анортозитах Патчемварекского массива (Морозова, 2018). Возрастные характеристики данных интрузий долгое время являлись предметом дискуссии. По данным (Кудряшов, Мокрушин, 2011) время формирования массива Патчемварек составляет $2925 \pm 6$ млн. лет, массива Северный $-2935 \pm 8$ млн. лет, что позволяет рассматривать породы массивов как фрагмент древнего протолита догранулитовых и догранитных ассоциаций Мурманского микроконтинента (Минц и др., 2010). По данным (Вревский, Львов, 2016) габбро-анортозиты массива Патчемварек сформированы $2661.8 \pm 7.1$ млн. лет назад, что в пределах ошибок совпадает с возрастом других габбро-анортозитовых массивов Кейвского блока Кольско-Норвежской провинции Фенноскандинавского щита.

В данной статье акцентировано внимание на петрографических характеристиках пород массивов и их петро-геохимических особенностях. Материал был собран в ходе полевых работ, направленных на изучение литиевых пегматитов Колмозерского месторождения. 


\section{Результаты исследования}

Патчемварекский массив метагаббро-анортозитов представляет собой крутопадающую $\left(50-80^{\circ}\right)$ на северо-восток тектоническую пластину шириной до 2 км и длиной $\sim 7$ км. Контакты метагаббро-анортозитов с трондьемитовыми гнейсами Мурманского блока и метаморфизованными породами зеленокаменного комплекса Колмозеро-Воронья тектонизированные и в северовосточной части затушеваны более поздними метасоматическими изменениями, связанными с внедрением пегматитовых расплавов. Основная часть массива сложена лейкократовыми $(\mathrm{Pl}=70-85 \%$; $\mathrm{Amf}=30-25 \%)$ и мезократовыми $(\mathrm{Pl}=40-60 \%$; $\mathrm{Amf}=40-60 \%)$ метагаббро и метаанортозитами $(\mathrm{Pl}=90-100 \%, \mathrm{Amf}=0-10 \%)$ крупно- среднезернистой структуры, массивной текстуры. В южной части массива отмечаются участки пород пятнистой структуры, характеризующиеся обособленным распределением темноцветных минералов и плагиоклаза. Наиболее измененные разности пород, представленные мелкозернистыми сланцеватыми ортоамфиболитами, приурочены к краевым частям массива.

Метагаббро (рис. 1) бластогаббро-офитовой структуры состоят из полисинтетически сдвойникованных субидиоморфных кристаллов лабрадора-битовнита $\left(\mathrm{An}_{64-85}\right)-\mathrm{Pl}-\mathrm{I}$, интерстиции между которыми выполнены нематобластовым агрегатом кристаллов зеленоватого амфибола, по составу отвечающего амфиболу тремолит-актинолитового ряда и магнезио-горнблендиту. В зональных зернах P1-I центральные части имеют более основной состав $\left(\mathrm{An}_{71}\right)$ по сравнению с краевыми зонами $\left(\mathrm{An}_{64}\right)$. Более поздний андезин $\left(\mathrm{An}_{47-50}\right)$ - Pl-II, замещает кристаллы лабрадора-битовнита и образует несдвойникованные ксеноморфные зерна. Зерна P1-I амфиболизированы, эпидотизированы. Отмечаются зерна P1-I с изогнутыми границами двойниковых швов.

Амфиболизированные и эпидотизированные метаанортозиты гипидиоморфнозернистой структуры состоят из длиннопризматических кристаллов лабрадора-битовнита длиной 8-10 мм. Акцессорные минералы: титанит, апатит, титаномагнетит, пирит, пирротин, халькопирит.

Ортоамфиболиты нематобластовой и гранонематобластовой структуры иногда с реликтами габбровой структуры состоят из мелкозернистого амфибола ряда тремолит-актинолита и не-
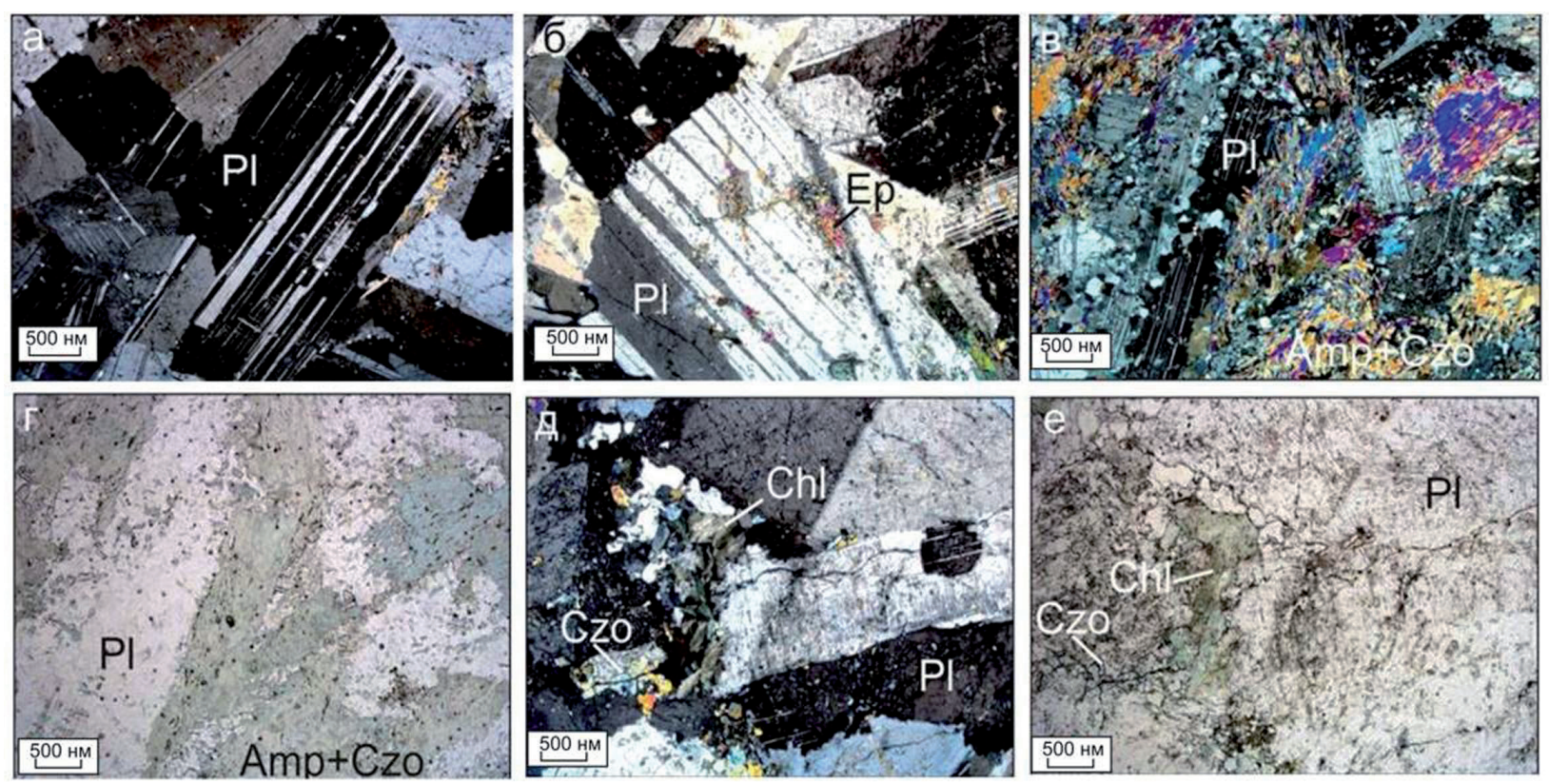

Рис. 1. Габброиды массива Большой Патчемварек. Фото прозрачных шлифов.

Pl - плагиоклаз; Еp - эпидот; Amp - амфибол; Czo - клиноцоизит; Chl - хлорит. а, б, в, д, - николи скрещены; г, е - без анализатора.

Fig. 1. Gabbroids of the Bolshoi Patchvarev massif. Photo transparent thin sections.

Pl - plagioclase; Ep - epidote; Amp - amphibole; Czo - clinozoisitis; Chl - chlorite. a, b, c, d, - Nicols are crossed; $\mathrm{g}$, e - without analyzer. 

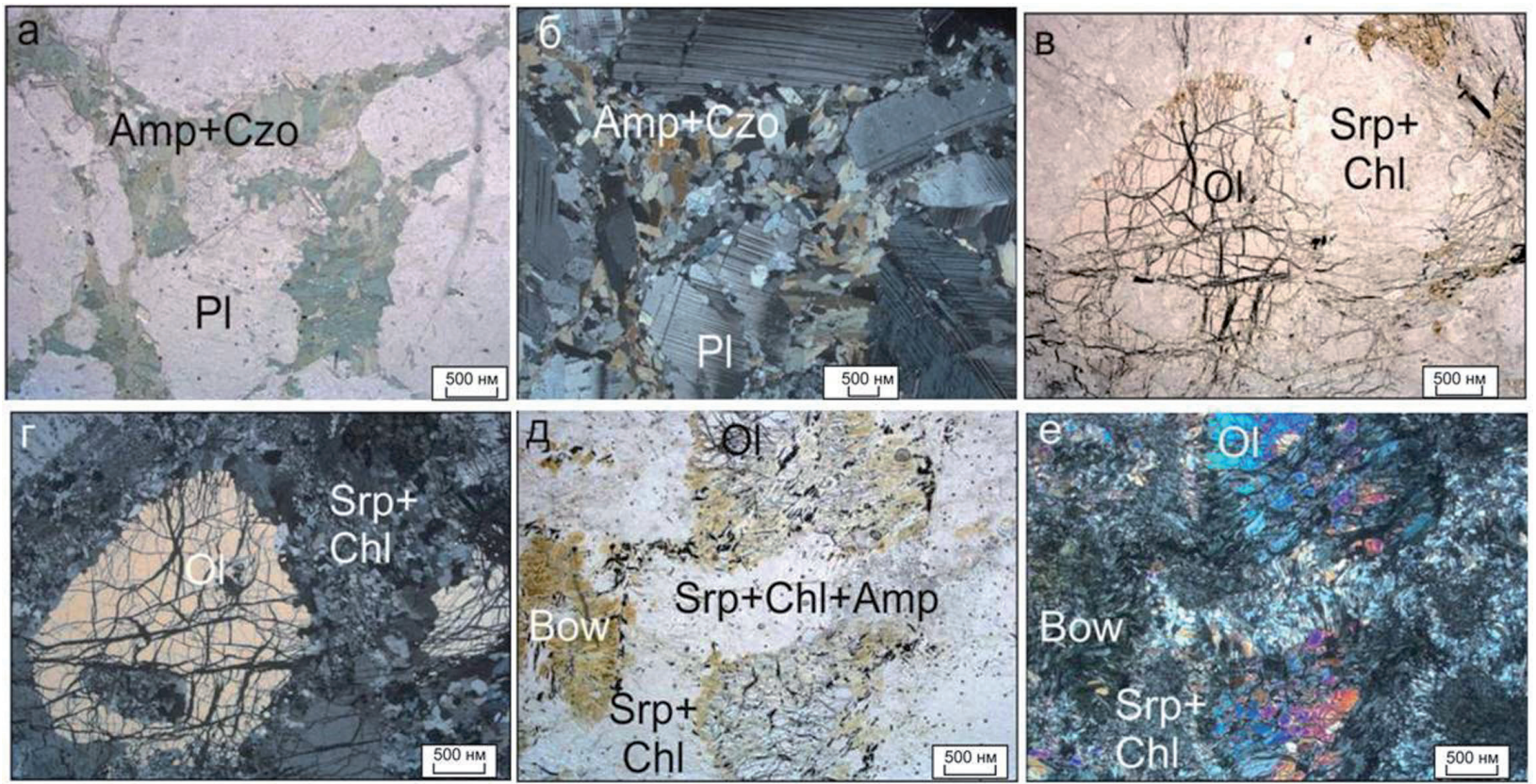

Рис. 2. Породы массива Северный. Фото прозрачных шлифов.

$\mathrm{Pl}$ - плагиоклаз; Ol - оливин; Srp - минералы семейства серпентинов; Bow - боулингит; Аmp - амфибол; Czo - клиноцоизит; Chl - хлорит. а, б, в, д, ж - николи скрещены; г, е - без анализатора.

Fig. 2. Rocks of the Severnyy massif. Photo of transparent thin sections.

$\mathrm{Pl}$ - plagioclase; Ol - olivine; Srp - minerals of the serpentine family; Bow - bowling; Amp - amphibole; Czo - clinozoisitis; Chl - chlorite. a, b, c, d, g- Nicols are crossed; g, e - without analyzer.

сдвойникованного плагиоклаза (олигоклаз-андезин) в соотношении 1:1. Эпидотовые и эпидотроговообманковые амфиболиты включают плагиоклаз (30-40 \%), роговую обманку (40-45 \%), эпидот (до 35 \%), титанит (до 10 \%) и клиноцоизит. Титанит в виде губчатых зерен неправильной формы слагает шлиры длиной до 3-4 мм, расположенные согласно с общей директивностью породы.

Рассеянная сульфидная минерализация в породах массива Патчемварек представлена пирротином, халькопиритом, пиритом, сфалеритом, единичными зернами сперрилита и гессита (Mokrushin et al., 2017).

Северный массив метагаббро-анортозитов линзообразной формы имеет протяженность $\sim 4$ км при ширине $\sim 2$ км. Основная часть массива сложена метагаббро и метаанортозитами аналогичным вышеописанным. В юго-западной части массива отмечаются выходы метаультрамафитов. По мнению Юдина Б.А (1980), Шаркова Е.В. (1984) и некоторых других исследователей, ультраосновные породы представляют собой дифференциаты единого с габбро и анортозитами дифференцированного комплекса.

По минеральному составу среди пород массива Северный выделены метапироксениты $(\mathrm{Ol}=5-40 \%)$, метаперидотиты $(\mathrm{Ol}=45-50 \%)$ и серпентиниты. Кроме оливина в метаультрамафитах отмечается амфибол (10-40 \%), серпентин (10-85 \%), также присутствуют хлорит и магнетит (рис. 2).

Оливин представлен реликтами зерен, в отдельных случаях окруженных радиальнолучистыми амфиболовыми каймами. Оливин замещается шнуровидными агрегатами лизардита, магнетита и боулингита. Интерстиции между зернами оливина выполнены пластинчатым антигоритом, хлоритом, амфиболом тремолит-актинолитового ряда, магнетитом. Амфиболизированные серпентиниты нематобластовой или пойкилобластовой структуры с фибробластовой основной тканью сложены серпентином, по оптическим свойствам диагностированным как антигорит. Бесцветный амфибол тремолит-актинолитового ряда образует зерна в массе антигорита или формирует скопления овальной формы длиной около 2 мм. Магнетит (2-5 \%) представлен вкрапленностью с размером зерен до 1 мм. 
Изучение химического и редкоэлементного состава пород показало, что изученные породы относятся к семействам перидотитов и габброидов нормальной щелочности. В нормативных составах метагаббро и метаанортозитов присутствует оливин: 3.05 (мол. к-ва) и 0.71 (мол. к-ва), соответственно. Величина магнезиальности (mg\#) понижается от метаперидотитов (0.85) к метагаббро (0.57) и метаанортозитам (0.34). Высокое значение магнезиальности в метаперидотитах коррелируется с повышенными содержаниями Со и $\mathrm{Ni}$ и пониженными содержаниями высокозарядных (Zr, Hf, Cs, Nb, Y, Th, U, REE) и крупноионных литофильных (Ba, Rb, Sr, K) элементов.

Метагаббро $(\Sigma \mathrm{REE}=15.67$ г/т; $(\mathrm{La} / \mathrm{Yb}) \mathrm{N}=1.82-3.01)$ и метаанортозиты $(\Sigma \mathrm{REE}=27.56$ г/т; $(\mathrm{La} / \mathrm{Yb}) \mathrm{N}=3.40-3.72)$ отличаются от метаперидотитов $(\Sigma \mathrm{REE}=5.35$ г/т) повышенными содержаниями REE, более дифференцированными спектрами распределения редкоземельных элементов и наличием положительной $\mathrm{Eu}$ аномалии $\left(\mathrm{Eu} / \mathrm{Eu}^{*}=1.27-2.60\right)$ (рис. 3 a). Положительная Еu аномалия может свидетельствовать о накоплении плагиоклаза в процессе фракционирования исходного расплава.

От метагаббро $\left((\mathrm{La} / \mathrm{Sm})_{\mathrm{N}}=1.67-2 / 34 ;(\mathrm{Gd} / \mathrm{Yb})_{\mathrm{N}}=0.99-1.18\right)$ к метаанортозитам $\left((\mathrm{La} / \mathrm{Sm})_{\mathrm{N}}=2.33-2.62 ;(\mathrm{Gd} / \mathrm{Yb})_{\mathrm{N}}=1.13-1.12\right)$ отмечается рост LREE при сопоставимых содержаниях MREE и HREE. Это может указывать на накопление легких лантаноидов в остаточном расплаве в процессе дифференциации магматического расплава.

На графиках распределения несовместимых элементов, нормированных к примитивной мантии (рис. 3 б), проявлены отрицательные аномалии Ва и Nb, положительная аномалия Тh и относительное обогащение пород Cs и Rb. Различие заключаются в том, что для метагаббро и метаанортозитов установлена положительная аномалия Sr, в то время как для метаперидотитов - отрицательная. Это может свидетельствовать о комплементарности составов пород массивов и участии плагиоклаза в процессе фракционирования исходного расплава.

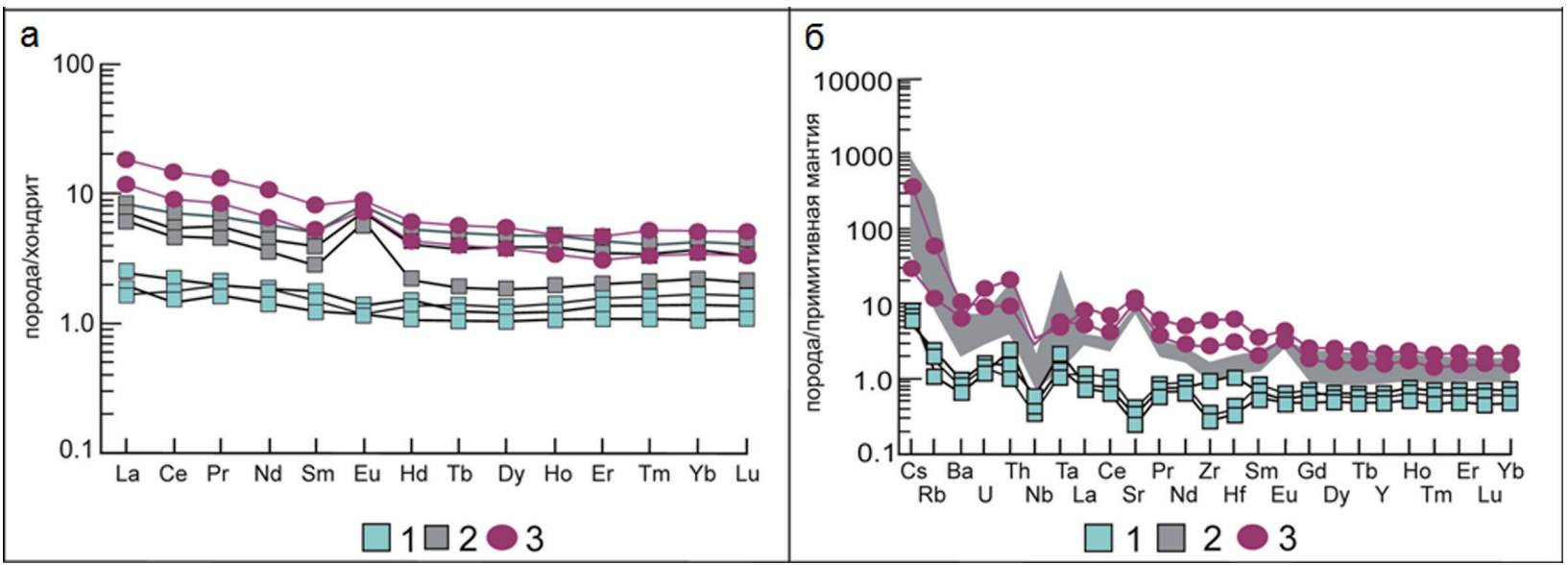

Рис. 3. Распределение редкоземельных и несовместимых элементов в метаперидотитах (1), метагаббро (2) и метаанортозитах (3) Патчемварекского и Северного массивов.

a - нормировано по хондриту (Boynton, 1984); б - нормировано по примитивной мантии (Sun, McDonough, 1989).

Fig. 3. Distribution of rare earth and incompatible elements in and metaperidotites (1), metagabbro (2) and metaanorthosites (3) from Patchemvarek and Severny massifs.

$\mathrm{a}$ - chordrite-normalized (Boynton, 1984); b - normalized to the composition of primitive mantle (Sun, McDonough, 1989).

\section{Выводы}

На основании полученных данных (сходство и закономерное распределение редких элементов в соответствии с магнезиальностью) можно подтвердить высказанное ранее рядом авторов предположение о том, что породы массивов являются дифференциатами единого магматического расплава и слагают расслоенный комплекс, включающий ультраосновные и основные кумулаты. При 
этом метаперидотиты принадлежат приподошвенным частям интрузии, а метагаббро и метаанортозиты - вышележащим горизонтам, обогащенным плагиоклазом.

Относительное обогащение пород $\mathrm{Cs}$, $\mathrm{Rb}$ и $\mathrm{Th}$ и высокие отношения $\mathrm{Th} / \mathrm{Ta}$ (до 13.50) могут свидетельствовать о контаминации исходных расплавов веществом архейской континентальной коры.

Авторы выражают благодарность П.А. Серову за участие в полевых работах.

Работа выполнена в рамках темы НИР № 0226-2019-0053.

\section{Литература}

1. Вревский А.Б., Львов П.А. Изотопный возраст и гетерогенность источников габбро-анортозитов массива Патчемварек (Кольский полуостров) // Доклады АН. 2016. Т. 469. № 2. С. 204-209.

2. Кудряшов Н.М., Мокрушин А.В. Мезоархейский габбро-анортозитовый магматизм Кольского региона: петрохимические, геохронологические и изотопно-геохимические данные // Петрология. 2011. Т. 19. № 2. C. $173-189$.

3. Минц М.В., Сулейманов А.К., Бабаянц П.С. и др. Глубинное строение, эволюция и полезные ископаемые раннедокембрийского фундамента Восточно-Европейской платформы: Интерпретация материалов по опорному профилю 1-ЕВ, профилям 4В и ТАТСЕЙС. М.: ГЕОКАРТ: ГЕОС. 2010. Т. 1. 408 с.

4. Морозова Л.Н. Колмозерское литиевое месторождение редкометалльных пегматитов: новые данные по редкоэлементному составу (Кольский полуостров) // Литосфера. 2018. Т. 18. № 1. С. 82-98.

5. Шарков Е.В. Анортозитовые ассоциации Кольского полуострова. Анортозиты Земли и Луны. М. Изд-во: Наука. 1984. С. 5-61.

6. Юдин Б.А. Габбро-лабрадоритовая формация Кольского полуострова и ее металлогения. Л. Изд-во: Наука. 1980. 168 с.

7. Boynton, William V. Cosmochemistry of the rare earth elements : meteorite studies. Rare Earth Element Geochemistry. editor / P. Henderson. Elsevier, 1983. P. 63-114.

8. Mokrushin A.V., Kudryashov N.M., Gabov D.A., Huber M. Sulphide and precious metal mineralization of the Mesoarchean Patchemvarek gabbroanorthosite Massif (Kola region, Russia) / Материалы V Международной конференции. Улан-Удэ. Бурятский государственный университет. 2017. С. 191-192.

9. Sun S.-S., McDonough W.F. Chemical and isotopic systematic of oceanic basalts: Implications for mantle composition and processes. Magmatism in the Ocean Basins. 1989.Norrys. Oxford. Geological Society Spec. Publ. V. 42. P. 313-345. 